\title{
Adenosine Triphosphate (ATP) in the MCF-12A Epithelial Cell: Square Wave (150 Hz Pulsed Saw Tooth-like Waveform) versus AC Electric Stimula- tion in vitro
}

\author{
Dirk Van Papendorp, Alida Koorts, Annie Joubert and Mona-Liza Lottering \\ Dept of Physiology, School of Medicine, Faculty of Health Science, University of Pretoria, Pretoria, South Africa \\ (Received 23 November 2002; and accepted 25 November 2002)
}

\begin{abstract}
Electrotherapy has been used for a variety of clinical conditions with varying results. In 1982 it was shown that a small DC current leads to an increase in ATP generation. ATP has been implicated as a peripheral mediator of pain. This study compared the effects of an AC TENS (transcutaneous electric nerve stimulation) device to a DC operated MET (micro-current electric therapy) device, on ATP levels in cultured cells. MCF-12A epithelial cells were exposed to either a $600 \mu \mathrm{A}$ micro-current DC field or a $\mathrm{mA}$ current AC field. Intracellular and extracellular ATP levels were measured by chemiluminescence. Extracellular ATP secretion from MCF-12A cells was found to be 27.7-fold after micro-current DC treatment, compared to 2.5-fold after conventional $\mathrm{AC}$ treatment. However, neither electric modality resulted in net ATP production. Cell morphology was not affected by either strategy. A hypothesis for the mechanism of micro-DC in pain modulation is proposed, whereby extracellular ATP is degraded to adenosine, a strong analgesic agent.
\end{abstract}

Extensive research has shown that, apart from its well-known intracellular effects, adenosine triphosphate (ATP) also has many extracellular physiological functions (4). Extracellular ATP has been identified as a ligand, as a transmitter and also as a co-transmitter that affects numerous cellular functions by activating $\mathrm{P} 2$-purinergic receptors (8). The two major classes of $\mathrm{P} 2$-receptors are $\mathrm{P} 2 \mathrm{X}$ - and P2Y-receptors. The ATP-dependent P2X receptors are ligand-gated channels that can be permeable to either sodium, potassium or calcium ions. Via these channels, extracellular ATP can cause depolarisation or increased intracellular calcium levels in activated cells $(4,8,14)$. P2Y-receptors are G-protein coupled and activate phospholipase $C$. Through the formation of $\mathrm{IP}_{3}$ (inositol-3-phosphate), intracellular cal-

Correspondence to: Professor Dirk Van Papendorp, Dept of Physiology, PO Box 2034, 0001, Pretoria, South Africa

Tel: +27123192175 , Fax: +27 123211679

E-mail: dvanpape@medic.up.ac.za cium levels are increased, which will then activate many calcium dependent cellular activities (14). The $\mathrm{P} 2 \mathrm{Y}_{11}$ receptor specifically activates adenylyl cyclase, causing increased cAMP production $(6,15)$. In addition, phospholipase $\mathrm{A} 2$ is also activated by extracellular ATP, which can lead to increased levels of arachidonic acid in the stimulated cells (15, 20). The proliferative effects of ATP are also mediated by $\mathrm{P} 2 \mathrm{Y}$ receptors. Pulsatile releases of ATP give a growth signal mediated by the intracellular pathways usually activated by conventional growth factors $\left(\mathrm{Ca}^{2+}, \mathrm{IP}_{3}\right.$ diacylglycerol kinases etc.) The positive effects of electric stimulation on bone fracture healing and tissue regeneration have been attributed to activation of some of these signal transduction mechanisms $(2,19)$. Apart from the functions mentioned above, a possible role for extracellular ATP as an inducer and mediator of the pain sensation has also been described $(3,12,24)$. The ATP/adenosine system is a novel target for nociceptive modulation.

We investigated the effects of in vitro exogenous 
electric stimulation on intra- and extracellular levels of ATP respectively, in MCF-12A cells. Morphological evaluation of possible cytotoxic effects of the electric stimulation on MCF-12A cells was also performed.

\section{MATERIALS AND METHODS}

Cell lines. Experiments were performed on MCF$12 \mathrm{~A}$ cells, supplied by the American Type Culture Collection (USA). The MCF-12A cell line is an adherent non-tumorigenic epithelial cell line produced by long-term culture of normal human mammary tissue.

Cell culture maintenance and chemicals. Heat inactivated fetal calf serum (FCS), minimum essential medium (MEM) and sterile plastic plates were obtained from Sterilab Services (Kempton Park, South Africa). Phosphate buffered saline (PBS) was supplied by Gibco BRL (USA). All other chemicals were of analytical grade and supplied by Sigma Chemical Co.

ATP assay. The ATP Bioluminescence Assay Kit HS 11 was obtained from Roche Molecular Biochemicals (Randburg, South Africa).

Electric devices. APS Technologies Pty Ltd (Pretoria, South Africa) supplied a device delivering a direct micro-current electric field. The pulse waveform was a brief monophasic square pulse (duration 0.8 ms) followed by exponential decay to base level. The median of the applied current strength was set to $600 \mu \mathrm{A}$ for all the experiments, which corresponds to a peak voltage of approximately $10 \mathrm{~V}$ for the experiments. The applied signal translates into peak field strengths of approximately $10^{1}-10^{2} \mathrm{Vm}^{-1}$ in the samples. The pulse frequency used was 150 $\mathrm{Hz}$. The second apparatus was a conventional TENS (transcutaneous electric nerve stimulation) device (Omron E1 from Omron Healthcare Europe, Mannheim, Germany) that operates on $\mathrm{AC}$ pulses with peak strength in the $10^{-1}-10^{2} \mathrm{Vm}^{-1}$ range, with frequencies below $100 \mathrm{~Hz}$ and outputs in $\mathrm{mA}$ range.

Direct or alternating current electric stimulation of cells. Equal numbers of MCF-12A cells $\left(\sim 5 \times 10^{5} \mathrm{ce}-\right.$ lls/well) were seeded into six-well culture plates $(9.4$ $\mathrm{cm}^{2}$ surface area/well). The cell cultures were incubated for $24 \mathrm{~h}$ in MEM containing $10 \%$ heat inactivated fetal calf serum, $10 \mu \mathrm{L} / \mathrm{mL}$ penicillin, 10 $\mu \mathrm{L} / \mathrm{mL}$ streptomycin and $25 \mu \mathrm{L} / \mathrm{mL}$ fungi zone.
The cell cultures were incubated at $37^{\circ} \mathrm{C}$ in a humidified atmosphere containing $5 \% \mathrm{CO}_{2}$. After $24 \mathrm{~h}$ near confluent layers of $\mathrm{MCF}-12 \mathrm{~A}$ cells were washed three times with PBS $\left(37^{\circ} \mathrm{C}\right)$. Two $\mathrm{mL}$ of warm $\left(37^{\circ} \mathrm{C}\right)$ PBS was pipetted into each of the wells. The wells were fitted with electrodes embedded in resin. Electrodes in each well, attached to the two electric devices, were separated by $3.4 \mathrm{~cm}$, and were in electric contact with the PBS. Wells $(n>6)$ in the control group were left untreated, while those in the experimental group were subjected to either direct or alternating current electric stimulation for 8 minutes. All the experiments were performed in an incubator at $37^{\circ} \mathrm{C}$.

Measurement of intracellular and secreted ATP of $M C F-12 A$ cells. After electric stimulation of MCF$12 \mathrm{~A}$ cells, PBS samples were taken from each well for the measurement of secreted ATP. To measure intracellular ATP, the remaining PBS was discarded and the cells were lysed with the cell lysis reagent provided in the kit for $20 \mathrm{~min}$ at room temperature. Luciferase reagent $(200 \mu \mathrm{L})$ was added to $200 \mu \mathrm{L}$ of either PBS sample or cell lysate $(100 \times$ diluted $)$ and ATP content was measured according to protocol described in the pack insert of Roche's Bioluminescence assay kit. A BioOrbit 1251 Luminometer (O. E. N. Enterprises, SA) was used.

Morphological studies. It is well known that the membranes of cells exposed to large electric fields will undergo electroporation, causing the cell membrane to be permeable to a variety of molecules. To determine whether the applied electric field had any toxic effects on the cells $24 \mathrm{~h}$ after exposure, MCF$12 \mathrm{~A}$ cells were grown on cover slips to near confluency before being subjected to either AC or DC electric fields for $8 \mathrm{~min}$ as described above. After $24 \mathrm{~h}$, control and electrically treated cells were fixed in Bouin's fixative and stained with haematoxylin and eosin, using standard procedures. One thousand untreated as well as one thousand treated cells were counted. Mitotic indices and the percentage of necrotic and apoptotic cells were determined.

Statistics. The results were analyzed for statistical significance using the unpaired two-tailed Student's $t$ test, assuming equal variances. Means are presented in bar charts with error bars indicating the standard deviations of each sample. $P$ values $<0.01$ are regarded as statistically significant and indicated by an asterisk. 


\section{RESULTS}

A marked, highly significant increase in the release of ATP into the medium was seen in the micro-current DC electrically stimulated $\mathrm{MCF}-12 \mathrm{~A}$ cells compared to that of cells subjected to the conventional TENS (Fig. 1A). The cell membrane is not usually permeable to ATP, but it is a general finding that ATP is released into the media of cultured cells when there is a mechanical disturbance present, including the changing of medium (8). Therefore, as expected, a small amount of ATP was present in the media of control MCF-12A cells (Fig. 1A). Microcurrent DC electric stimulation, however, increased extracellular ATP 27.7-fold (Fig. 1A), indicating
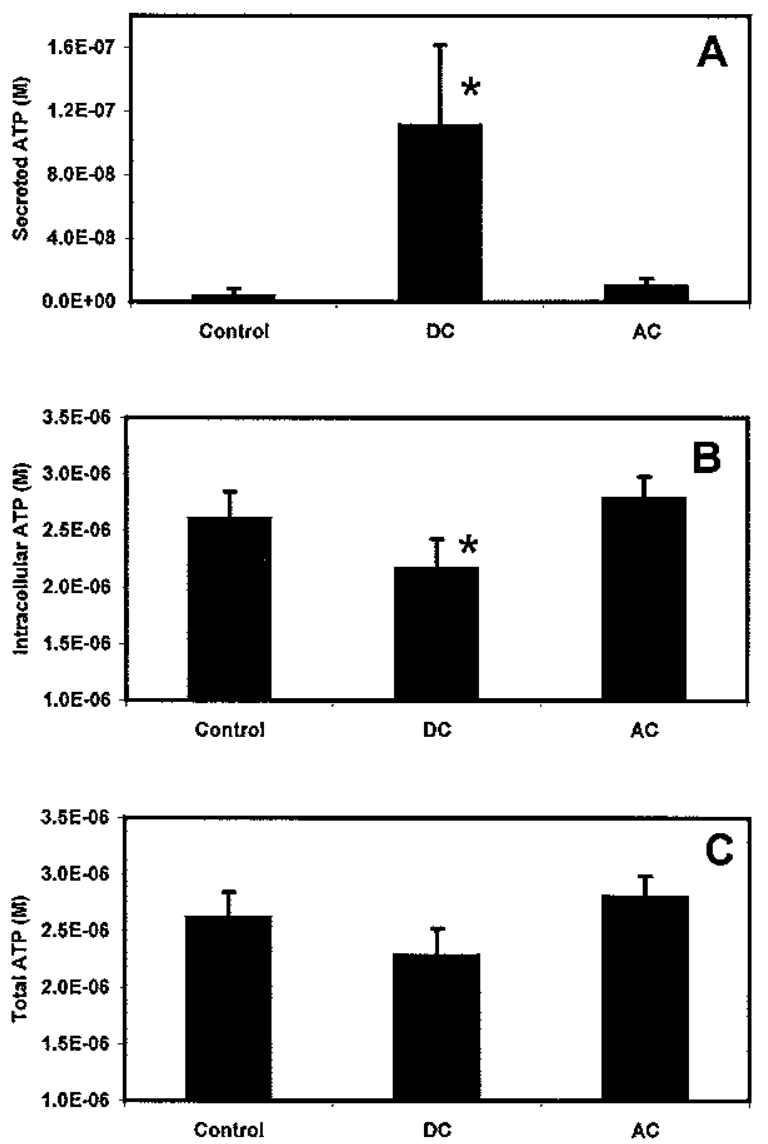

Fig. 1 Levels of ATP in MCF-12A cell cultures before and after electric stimulation. The release of ATP out of the cells (A) was significantly higher in the cells subjected to DC than in the control cells. Simultaneously, the intracellular ATP levels (B) significantly decreased in cultures that received DC treatment. The total ATP concentrations (C) (intracellular and secreted ATP combined) after treatment were not affected by electric stimulation. $(P<0.01)$ that an ATP-releasing mechanism in the membranes of the MCF-12A cells might have been activated. Only a marginal increase (2.5-fold) in secreted ATP levels were observed after AC stimulation (Fig. 1A).

Intracellular ATP levels were significantly decreased in the MCF-12A cells after micro-current DC stimulation, while AC treatment had no significant effect (Fig. 1B). The total concentration of ATP in each well (the combined value of secreted ATP and intracellular ATP) was not significantly affected by either $\mathrm{AC}$ or DC stimulation (Fig. IC), indicating that ATP synthesis was not affected by electric stimulation, but that micro-current DC treatment activates MCF-12A cells to secrete intracellular ATP.

No evidence of morphologically identifiable, cytotoxic effects was detected by light microscopy in the MCF-12A cells $24 \mathrm{~h}$ after electric treatment. There was also no significant effect on the number of dividing cells, nor were any abnormal mitotic figures present (Fig. 2). Similar numbers of all the mitotic phases were seen in the control and treated cells. The number of necrotic or apoptotic cells was also not increased after treatment (Fig. 2). Therefore, no lasting cell-damaging effects were observed in the MCF-12A cells $24 \mathrm{~h}$ after electric treatment.

\section{DISCUSSION}

ATP can be released from cells when damage occurs in the cell membrane (8). There are also physiologically important transport mechanisms of ATP across cell membranes, which include the release of cytosolic ATP through secretory vesicles and through specific ATP transporting systems $(13,18,23)$. From this study it is unclear how the ATP was released to such a large extent into the medium. The morphological study showed no cytotoxic effects or

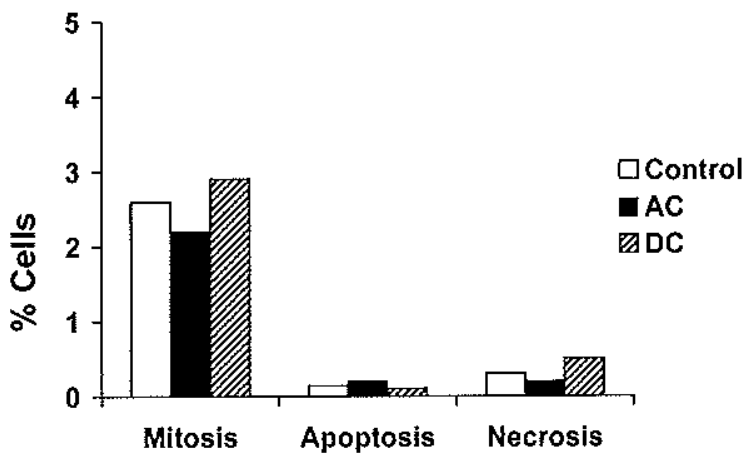

Fig. 2 Effects of electrical treatment on the percentage of mitotic, apoptotic and necrotic cells. Each value represents the average of a thousand cells counted. 
loss of membrane integrity in the MCF-12A cells (Fig. 2). We therefore conclude that a low-amplitude, periodic, pulsed DC field will enhance ATP release from MCF-12A cells.

Numerous membrane signal transduction mechanisms are activated, inhibited or mediated by extracellular ATP, since there are so many different purinergic receptors (8). The very high levels of electric field-stimulated ATP released in MCF-12A cells may therefore influence many cellular processes in the cells in an auto- or paracrine fashion. The cellular responses will depend on the type of purinergic receptors, PX2 (ion-channel linked) or PY2 (G-protein linked), present in the MCF-12A cell membranes. Apart from the effects on purinergic receptors, it has also been shown that extracellular ATP acts as a substrate for ectokinases (protein kinases that are active on the surface of cell membranes) in certain cultured cells (17) and may therefore influence the phosphorylation of extracellular membrane proteins. Extracellular ATP serves as a local signal of injury to recruit inflammatory cells and initiate tissue repair, e. g. during wound healing (7).

Adenosine, (an endogenous compound present in all cells) may be released from cells directly or via degradation of ATP. Adenosine is involved in many regulatory mechanisms in both physiological and pathophysiological conditions $(1,21)$. Pharmacologically, adenosine acts as a strong analgesic agent.

Electric modalities have been used for many years to control both acute and chronic pain. According to anecdotal reports, TENS is only effective in pain alleviation when the current is strong enough to be sensory. At these clinical levels of $80 \mathrm{~mA}$ ATP will not be generated, since it has been shown that any stimulation over $1000 \mu \mathrm{A}$ causes plateauing and then reduction in ATP (5). This may explain why, in our study, no statistically significant differences of ATP levels were found with TENS stimulation.

On the other hand, our results showed that MET (DC current) released significant amounts of ATP extracellularly, without any changes to cell morphology observed. We hypothesize that the ATP is degraded to adenosine, which in turn is responsible for the pain relief experienced with this type of electric therapy. ATP may thus act as a peripheral mediator of pain (12). Further contributing to the pain relief may be the growth-promoting activity reported in several experimental observations $(9,10,11,16)$, as well as the reduction in inflammation, oedema, swelling, wound healing, etc $(22,25)$.

\section{REFERENCES}

1. Abbracchio M. P., and Burnstock G. (1998) Purinergic signalling: patho-physiological roles. Jpn. J. Phammacol. 78, 113145.

2. Bassett C. A. L. (1993) Beneficial effects of electromagnetic fields. J. Cell. Biochem. 51, 387-393.

3. Bland-Ward P. A., and Humphrey P. P. A. (2000) P2X receptors mediate ATP-induced primary nociceptive neurone activation. J. Auton. Nerv Syst. 81, 146-151.

4. Burnstock G., Mc Mahon S. B., Humphrey P. P. A., and Hamilton S. G. (2000) ATP (P2x) Receptors and Pain proceedings of the 9th World Congress on Pain. In: Divor M, Rowbotham MC, Wiesenfeld- Hallin Z, eds. Progress in Pain Research and Management. Seattle: IASP Press, 16, 63-76.

5. Cheng N., Van Hoof H., Bockx E., Hoogmartens M. J., Mulier J. C., De Dijcker F. J., Sansen W. M., and De Loecker W. (1982) The effect of electric currents on ATP generation protein synthesis, and membrane transport in rat skin. Clin. Orthop. 171, 264-272.

6. Communi D., Govaerts C., Parmentier C., and Bocynaems JM. (1997) Cloning of human purinergic P2Y receptor collpled to phospholipase $\mathrm{C}$ and adenylyl cyclase. $J$. Biol. Chem. 272, 31969-31973.

7. Di Virgillo F. (2000) Dr. Jekyll/Mr. Hyde: the dual role of extracellular ATP. J. Auton. Nerv. Syst. 81, 59-63.

8. Dubyak G. R., and EL-Moatassim C. (1993) Signal transduction via $\mathrm{P}_{2}$-purinergic receptors for extracellular ATP and other nucleotides. Am. J. Physiol. 265, C577-C606.

9. Fitzsimmons R. J., Strong D. D., Mohan S., and Baylink D. J. (1992) Low-amplitude, low frequency electric field-stimulated bone cell proliferation may in part be mediated by increased IGF-JI release. J. Cell. Physiol. 150, 84-89.

10. Goldman R., and Pollack S. (1996) Electric fields and proliferation in a chronic wound model. Bioelectromagnetics 17, 450-457.

11. Guigni T. D., Braslau L., and Haigler H. T. (1987) Electric field-induced redistribution and post field relaxation of epidermal growth factor receptors on A431 cells. J. Cell. Biol. 104, 1291-1297.

12. Hamilton S. G, and McMahon S. B. (2000) ATP as a peripheral mediator of pain. J. Auton. Nerv. Syst. 81, 187-194.

13. Katsugari T., Tokunaga T., Ohba M., Sato $C_{\text {., }}$ and Furukawa T. (1993) Implication of ATP released from atrial, but not papillary, muscle segments of guinea pig by isoproterenol and forskolin. Life Sci. 53, 961-967.

14. Kennedy C. (2000) The discovery and development of P2 receptor subtypes. J. Auton. Nerv. Syst. 81, 158-163.

15. Kennedy C., Qi A., Nicholas R. A., and Harden T. K. (1999) Differential coupling of the human $\mathrm{P} 2 \mathrm{Y}_{\mathrm{H}}$ receptor to phospholipase $C$ and adenylyl cyclase. Br: J. Pharmacol. 126, 22.

16. Korensein R., Somjen D., Fischler H., and Binderman I. (1984) Capacitative pulsed electric stimulation of bone cells. Induction of cyclic-AMP changes and DNA synthesis. Biochim. Biophys. Acta 803, 302-307.

17. Kubler D., Pyerin W., and Kinzel V. (1982) Protein kinase activity and substrates at the surface on intact HeLa cells. $J$. Biol. Chem. 257, 322-329.

18. Lader A. S., Xiao Y. F, O'Riordan C. R., Prat A. G., Jackson G. R. Jr., and Cantiello H. F. (2000) cAMP activates an ATPpermeable pathway in neonatal rat cardiac myocytes. Am. $J$. Physiol. Cell. Physiol. 279, C173-C187.

19. Lorich D. G, Brighton C. T., Gupta R., Corsetti J. R., Levine S. E., Gelb I. D., Seldes R, and Pollack S. R. (1998) Bio- 
chemical pathway mediating the response of bone cells to capacitive coupling. Clin. Orthop. 350, 246-258.

20. Ostrom R. S., Gregorian A., and Insel P.A. (2000) Cellular release of and response to ATP as key determinants of the setpoint of signal transduction pathways. J. Biol. Chem. 275, 11735-11739.

21. Pelleg A., and Porter R. S. (1990) The pharmacology of adenosine. Pharmacotherapy 10, 157-174.

22. Reich J. D., and Tarjan P. P. (1990) Electrical stimulation of skin. Int. J. Derm. 29, 395-400.

23. Roman R. M., Wang Y., Lidofsky S. D., Feranchak A. P.,
Lomri N., Scharschmidt B. F., and Fitz J. G. (1997) Hepatocellular ATP-binding cassette protein expression enhances ATP release and autocrine regulation of cell volume. J. Biol. Chem. 272, 21970-21976.

24. Souslova V., Cesare P., Ding Y., Akopian A. N., Stanfa L., Suzuki R., Carpenter K., Dickenson A., Boyce S., Hill R., Nebenuis-Oosthuizen D., Smith A. J., Kidd E. J., and Wood J. N. (2000) Warm-coding deficits and aberrant inflammatory pain in mice lacking $\mathrm{P} 2 \mathrm{X} 3$ receptors. Nature 407, 1015-1017.

25. Stanish W. D. (1985) The use of electricity in ligament and tendon repair. Physician and Sportsmedicine 13, 109-116. 